\title{
EFFICIENCY OPTIMIZATION OF SLITTED-CORE INDUCTION MOTOR
}

\author{
Asim Gökhan Yetgin * Mustafa Turan **
}

\begin{abstract}
In this study, a $3 \mathrm{~kW}$ squirrel cage induction motor having slits in stator and rotor teeth were examined. The slit depth and width in the 56 different slitted motor models were optimized with Finite Element Method Magnetics (FEMM) software by using Finite Elements Method (FEM). What value the depth and width of optimum slit should be was determined in order to obtain maximum motor efficiency in the new motor models created with the proposed slitted structure, and how the depth and width of slit could affect the performance of motor was demonstrated.
\end{abstract}

K e y w ords: induction motor, slit optimization, speed-efficiency characteristic

\section{INTRODUCTION}

The efficiency is of paramount importance nowadays because electrical motors are major consumers of electricity in the modern industrial society; they consume approximately $69 \%$ of electricity in the industry [1]. Threephase, low voltage squirrel cage induction motors are the most commonly used electric motors in industry. Efficiency data provided by manufacturers are measured or calculated according to certain standards. There are a lot of examples of agreements, incentives and initiatives worldwide in order to promote the efficiency [2]. There are many approaches in the literature to improve induction motor efficiency. Aho and et al investigated the effects of different motor materials on the performance of solid rotor induction motors in their studies. They carried out analysis by using slits in rotor structure. They stated that rotor flux distribution was better with slitted structure and the desired electromagnetic performance was achieved. But they stated that the mechanic strength was decreased and the cost of motor increased [3]. Aho and Nerg investigated the effects of the slit depth of solid rotor induction motor which had a slitted structure on the performance. They indicated that the slitted rotor created a better field distribution, but reduced the mechanical strength of rotor and it was difficult to analyse the slitted motor structure analytically. They suggested that the deeper the slit, the more torque was obtained, and a huge increase was obtained in the power factor value at the end of their study. They stated that the mechanical brittleness of rotor increased in the slitted forms which had bigger depth, and in order to prevent it, one short and one long slitted form could be used. Moreover, they stated that the depth of slit should be the half of the radius of the rotor [4]. Zaim, in his study, calculated with F.E.M. how motor performance changes according to the slit width, depth and number of the solid rotor induction motor. He showed that the more the slit depth increased, the more the torque increased at certain level and then it decreased. Moreover, he determined that the torque decreased as the width of slit increased. He stated that while torque first increased rapidly and then decreased as the number of slit increased in narrower slitted forms, in wider slits, the torque first increased and rapidly decreased. Furthermore, in that study, it was stated that rotor flux lines proceeded towards the inner sides of rotor by choosing the suitable slit depth and width [5]. Aho, Nerg and Pyrhnen, in their studies, examined the changes of magnetic rotor by adding slits to the rotor structure of solid rotor induction motor. They showed that when the number of slit was increased from 28 to 36 , the electromagnetic torque could be improved by $6 \%$ and power factor could a little be increased. Moreover, they stated that when the number of rotor slit numbers were increased saturation occurs between slits and so it worsened the electromagnetic performance. They showed that as the number of slit was increased, iron loses were increased [6]. In the study Nashiki et al, they placed slits on the rotor in order to decrease the torque oscillation and create magnetic flow in the direction of axis. They examined torque oscillations for the situations that had and did not have rotor skewing in slitted form. They stated that when the number of slit was low, the efficiency could increase but torque oscillations could also increase [7]. Akbari et al. proposed model which are calculated inductances of a three-phase squirrel-cage induction machine under eccentricity and misalignment conditions. They investigated the effects of stator and rotor slots, rotor skewing and several rotor asymmetries on inductances in these conditions [8]. By the time, the literature review has shown that the slitted structure has been more applied in solid rotor induction motors, hybrid excitation synchronous motors [9], reluctance synchronous machines [10] and switched reluctance motors [11].

Dumlupinar University, Faculty of Engineering, Department of Electrical and Electronics Engineering, 43100, Kutahya, Turkey, gokhan.yetgin@dpu.edu.tr; ${ }^{* *}$ Sakarya University, Faculty of Engineering, Department of Electrical and Electronics Engineering, 54050, Sakarya, Turkey, turan@sakarya.edu.tr 
Table 1. Motor models having different slit depth and width

\begin{tabular}{lcccccccccc}
\hline $\begin{array}{l}\text { Width } \\
\text { of slit } \\
(\mathrm{mm})\end{array}$ & 6.25 & 7.50 & 11.25 & 13.25 & 15.00 & 16.87 & 18.75 & 19.6 & 21.00 & 23.00 \\
\hline 0.09 & & $\mathrm{x}$ & $\mathrm{x}$ & $\mathrm{x}$ & $\mathrm{x}$ & $\mathrm{x}$ & $\mathrm{x}$ & & & \\
0.10 & $\mathrm{x}$ & $\mathrm{x}$ & $\mathrm{x}$ & $\mathrm{x}$ & $\mathrm{x}$ & $\mathrm{x}$ & $\mathrm{x}$ & $\mathrm{x}$ & $\mathrm{x}$ & $\mathrm{x}$ \\
0.15 & $\mathrm{x}$ & $\mathrm{x}$ & $\mathrm{x}$ & $\mathrm{x}$ & $\mathrm{x}$ & $\mathrm{x}$ & $\mathrm{x}$ & $\mathrm{x}$ & $\mathrm{x}$ & $\mathrm{x}$ \\
0.25 & & $\mathrm{x}$ & $\mathrm{x}$ & $\mathrm{x}$ & $\mathrm{x}$ & $\mathrm{x}$ & $\mathrm{x}$ & & & \\
0.50 & & $\mathrm{x}$ & $\mathrm{x}$ & $\mathrm{x}$ & $\mathrm{x}$ & $\mathrm{x}$ & $\mathrm{x}$ & & & \\
1.00 & & $\mathrm{x}$ & $\mathrm{x}$ & $\mathrm{x}$ & $\mathrm{x}$ & $\mathrm{x}$ & $\mathrm{x}$ & & & \\
1.50 & & $\mathrm{x}$ & $\mathrm{x}$ & $\mathrm{x}$ & $\mathrm{x}$ & $\mathrm{x}$ & $\mathrm{x}$ & & & \\
2.50 & & $\mathrm{x}$ & $\mathrm{x}$ & $\mathrm{x}$ & $\mathrm{x}$ & $\mathrm{x}$ & $\mathrm{x}$ & & & \\
\hline
\end{tabular}

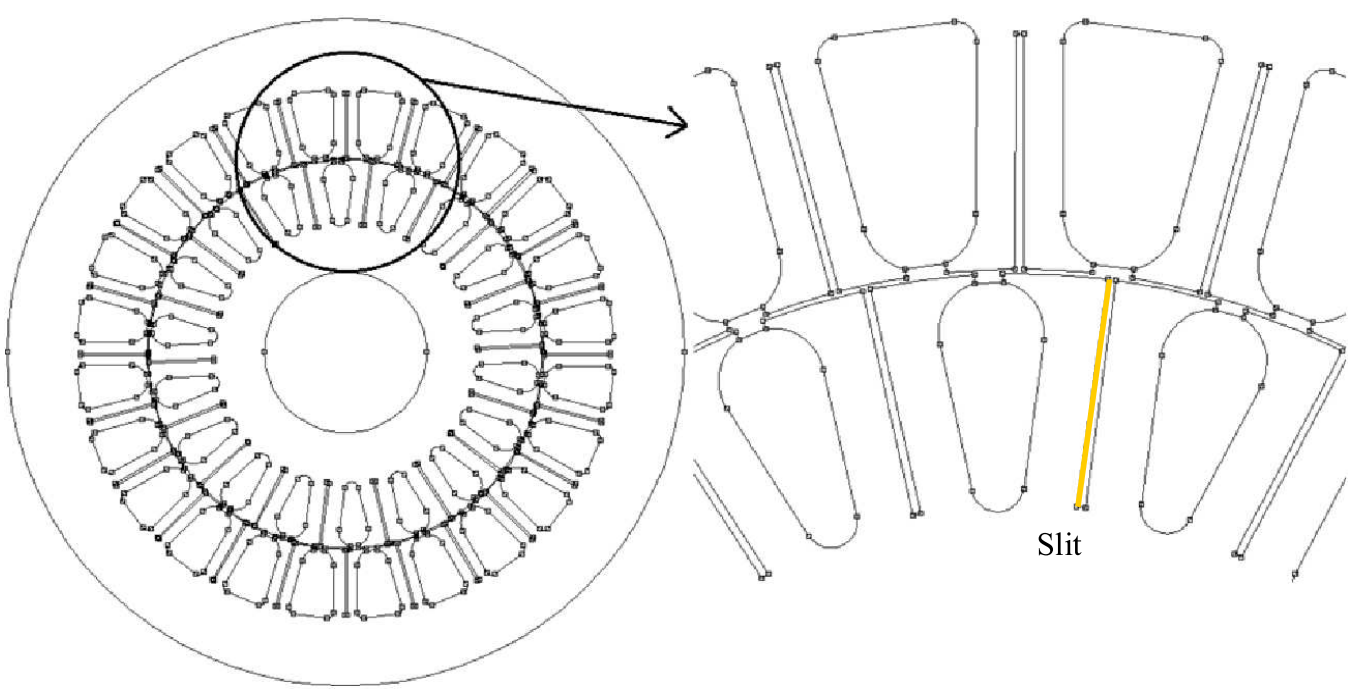

Fig. 1. Motor model with $15 \mathrm{~mm}$ slit depth and $0.25 \mathrm{~mm}$ slit width

In this study, slits were applied between the stator and rotor teeth of induction motor in the proposed design. How the efficiency of motor was changed in different slit depths and widths and optimum slit depth and width were determined for maximum motor efficiency.

\section{PROPOSED SLITTED CONSTRUCTION}

In our former paper, it was shown how zigzag fluxes around air gap would be decreased by using slitted structure motor models [12]. In that study it was also shown that there was $2.041 \%$ increase in coupling flux, resulting in an improvement in motor performance. Moreover, the result given in tables and graphics has shown that using well designed slits, it is possible to have a better flux density distribution in various points of the cores. In this study, how slit depth and width affect motor efficiency it is investigated. To observe efficiency changes, slits were applied in the middle of both stator and rotor teeth of squirrel-cage induction motor.
In the models, slit depths were chosen as $6.25 \mathrm{~mm}, 7.5$ $\mathrm{mm}, 11.25 \mathrm{~mm}, 13.125 \mathrm{~mm}, 15 \mathrm{~mm}, 16.875 \mathrm{~mm}, 18.75$ $\mathrm{mm}, 19.6 \mathrm{~mm}, 21 \mathrm{~mm}$ and $23 \mathrm{~mm}$ where the slit widths changing as $0.09 \mathrm{~mm}, 0.1 \mathrm{~mm}, 0.15 \mathrm{~mm}, 0.25 \mathrm{~mm}, 0.5$ $\mathrm{mm}, 1 \mathrm{~mm}, 1.5 \mathrm{~mm}$ and $2.5 \mathrm{~mm}$. For each slit depth with corresponding slit widths FEMM models are constructed. The aim here is to determine which slit depth and width provides the highest motor efficiency. By this manner, an optimization process has carried out on 56 different designs shown as $\mathrm{x}$ in Tab. 1 .

The motor model applied with the proposed slitted structure was shown in Figure 1. Other slitted motor models can be obtained from Reference [13]. The analysis were carried out by using the same values for all motor models without changing the parameters like stator and rotor slot shapes, inner and outer diameter, number of turns etc. The obtained results and charts were presented for full-load operation point.

Magnetic vector potential $(A)$, magnetic flux density $(B)$, current density and etc. are obtained from slitted motor models using FEM analysis. Efficiency values of motor models are determined that using the formula effi- 
ciency given in Reference [14] and additional software is written in Matlab.

\subsection{Advantages and Disadvantages of Proposed Construction Motor Model}

The advantages of proposed slitted construction according to reference motor are [13]:

- The more effective using of the magnetic flux for all the working areas: reduction of saturation, properly distribution of flux at the teeth, reduction of rotor reaction

- Decreasing additional losses: a properly flux distribution

- The reduction of loss values: loss values improve due to decreasing saturation and iron losses

- The reduction of slip: decreasing rotor copper loss

- The improvement of efficiency: the efficiency increases because of decreasing losses

- The improvement of performance at the nominal operating points

- The improvement of leakage reactance: the improvement of speed-torque characteristic

The disadvantage of the proposed slitted construction is:

- For small power motors, the initial construction cost is slightly high owing to cut off the core with laser.

For big power motors, there will be no extra cost due to the new mold to be created for mass production.

\section{DETERMINING OPTIMUM SLIT WIDTH AND THE EFFECT OF SLIT WIDTH ON MOTOR EFFICIENCY}

In this part, analyses were carried out to determine optimum slit width. The slit widths mentioned above were applied on the motor models having different slit depth and it was questioned which optimum slit width provides better motor efficiency. The obtained efficiency values for the motor models with $15 \mathrm{~mm}$ slit depth and different slit widths were given in Tab. 2. Obtained efficiency values on other slit depth were shown in Tab. 4. At the end of the analyses it was determined that the saturations occurring in the teeth increased as the slit width increased. It was determined that when the slit width value was especially at $0.25 \mathrm{~mm}$ and over, the saturations increased high enough to effect the efficiency. This was clearly shown with the efficiency values in Tab. 2.

Table 2. The obtained efficiency and relative difference values for the motor models with $15 \mathrm{~mm}$ slit depth and different slit widths [13]

\begin{tabular}{ccc}
\hline $\begin{array}{c}\text { Model slit } \\
(\mathrm{mm})\end{array}$ & $\begin{array}{c}\text { Efficiency } \\
(\%)\end{array}$ & $\begin{array}{c}\text { Relative } \\
\text { difference }(\%)\end{array}$ \\
\hline $\mathrm{RM}$ & 78.96 & \\
0.09 & 78.22 & -0.95 \\
$\underline{0.10}$ & $\underline{80.44}$ & $\underline{+1.87}$ \\
0.15 & 79.81 & +1.08 \\
0.25 & 76.79 & -2.76 \\
0.50 & 78.27 & -0.88 \\
1.00 & 73.25 & -7.23 \\
1.50 & 71.66 & -9.25 \\
2.50 & 55.89 & -29.2 \\
\hline
\end{tabular}

Table 3. The efficiency and relative difference values obtained for $0.1 \mathrm{~mm}$ slit width different slit depths motor models [13]

\begin{tabular}{ccc}
\hline $\begin{array}{r}\text { Model slit } \\
(\mathrm{mm})\end{array}$ & $\begin{array}{c}\text { Efficiency } \\
(\%)\end{array}$ & $\begin{array}{c}\text { Relative } \\
\text { difference }(\%)\end{array}$ \\
\hline $\mathrm{RM}$ & 78.96 & \\
6.25 & 77.87 & -1.38 \\
7.50 & 80.37 & +1.77 \\
11.25 & 80.32 & +1.71 \\
13.12 & 80.29 & +1.69 \\
$\underline{15.00}$ & $\underline{80.44}$ & $\underline{+1.87}$ \\
16.87 & 77.96 & +1.25 \\
18.75 & 79.77 & +1.02 \\
19.60 & 76.39 & -3.26 \\
21.00 & 75.62 & -4.24 \\
23.00 & 74.05 & -6.22 \\
\hline
\end{tabular}

Table 4. The efficiency values obtained in different slit depth and width [13]

\begin{tabular}{ccccccc}
\hline & \multicolumn{7}{c}{ Depth of Slit (mm) } \\
& 7.50 & 11.25 & 13.12 & 15.00 & 16.87 & 18.75 \\
\hline Width of Slit(mm) & \multicolumn{7}{c}{ Efficiency $(\%)$} \\
\hline 0.09 & 78.20 & 78.33 & 78.25 & 78.22 & 78.13 & 78.21 \\
0.10 & 80.37 & 80.32 & 80.30 & $\underline{80.44}$ & 79.96 & 79.77 \\
0.15 & 80.12 & 80.03 & 79.99 & 79.81 & 79.68 & 79.57 \\
0.25 & 80.03 & 79.97 & 79.95 & 76.77 & 79.43 & 79.54 \\
0.50 & 78.42 & 78.25 & 76.35 & 78.27 & 77.80 & 78.55 \\
1.00 & 73.59 & 73.49 & 73.41 & 73.25 & 72.84 & 72.18 \\
1.50 & 72.16 & 71.93 & 74.14 & 71.66 & 71.33 & 70.52 \\
2.50 & 56.53 & 56.23 & 56.05 & 55.89 & 56.39 & 55.00 \\
\hline
\end{tabular}




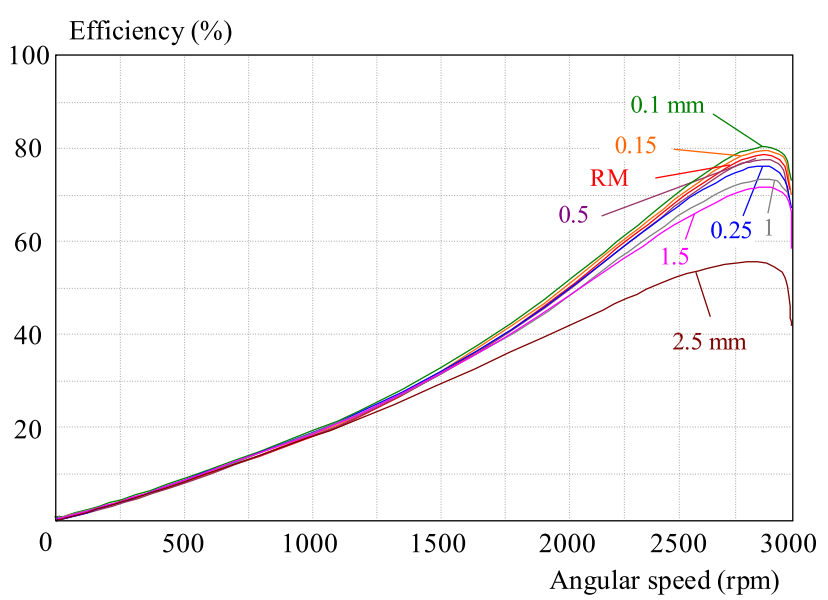

Fig. 2. Speed-efficiency curves obtained at different slit widths for $15 \mathrm{~mm}$ slit depth

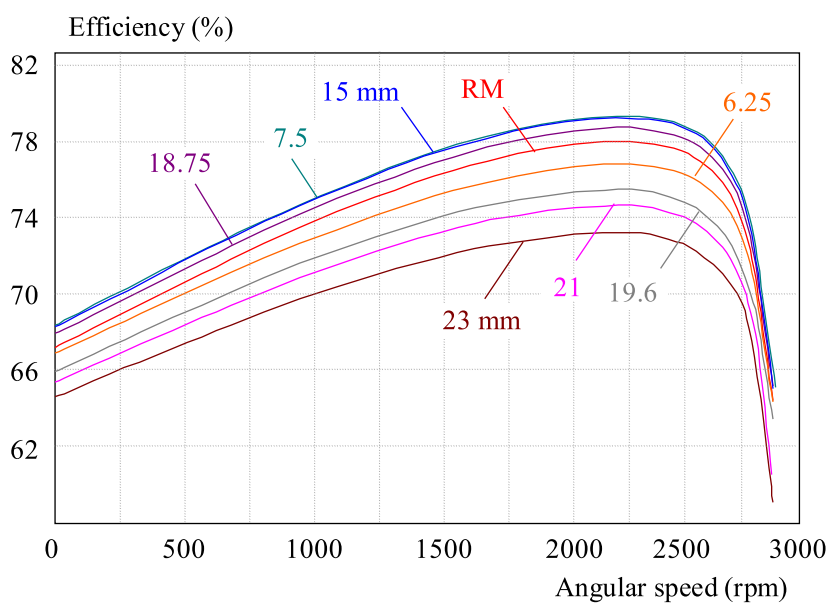

Fig. 3. Speed-efficiency curves obtained at different depths for 0.1 mm slit width

In Figure 2, speed-efficiency curves obtained at different slit widths for $15 \mathrm{~mm}$ slit depth were presented.

When the table and figure were examined, it was seen that the values obtained from $0.1 \mathrm{~mm}$ and $0.15 \mathrm{~mm}$ motor models were higher than the ones obtained from reference motor models. At the end of the analyses, it was seen that the efficiency value obtained from the motor model that had $0.09 \mathrm{~mm}$ slit width gave worse results than the value obtained from the $0.1 \mathrm{~mm}$ slit width which gave the best efficiency value. It was seen that the efficiency value decreased as the slit width increased depending on the increase of magnetic flow density amount. With these findings, it was determined that when the optimum slit width was 0.1 , motor efficiency was at maximum level [13].

\section{DETERMINING OPTIMUM SLIT DEPTH AND THE EFFECT OF SLIT DEPTH ON MOTOR EFFICIENCY}

Analyses were carried out at the following depths in order to determine optimum slit depth for each slit width.
Analyses were carried out by creating models having 6.25 $\mathrm{mm}, 7.5 \mathrm{~mm}, 11.25 \mathrm{~mm}, 13.125 \mathrm{~mm}, 15 \mathrm{~mm}, 16.875 \mathrm{~mm}$, $18.75 \mathrm{~mm}, 19.6 \mathrm{~mm}, 21 \mathrm{~mm}$ and $23 \mathrm{~mm}$ slit depths in order to determine optimum slit depth. The results for different slit depths having $0.1 \mathrm{~mm}$ slit width that gave maximum value in this study were presented in tables and charts. The relative values according to reference motor models and efficiency for 0.1 slit width different slit depths were given in Tab. 3. Obtained efficiency values on other slit width were shown in Tab. 4.

When the obtained results were examined, it was determined that minimum slit depth should be $7.5 \mathrm{~mm}$ and maximum slit depth should be $16.875 \mathrm{~mm}$. It was seen that the motor models that had $7.5 \mathrm{~mm}, 11.25 \mathrm{~mm}$, $13.125 \mathrm{~mm}$ and $15 \mathrm{~mm}$ slit depths had better efficiency than other motor models. But the motor model that had $15 \mathrm{~mm}$ slit depth gave the best efficiency value.

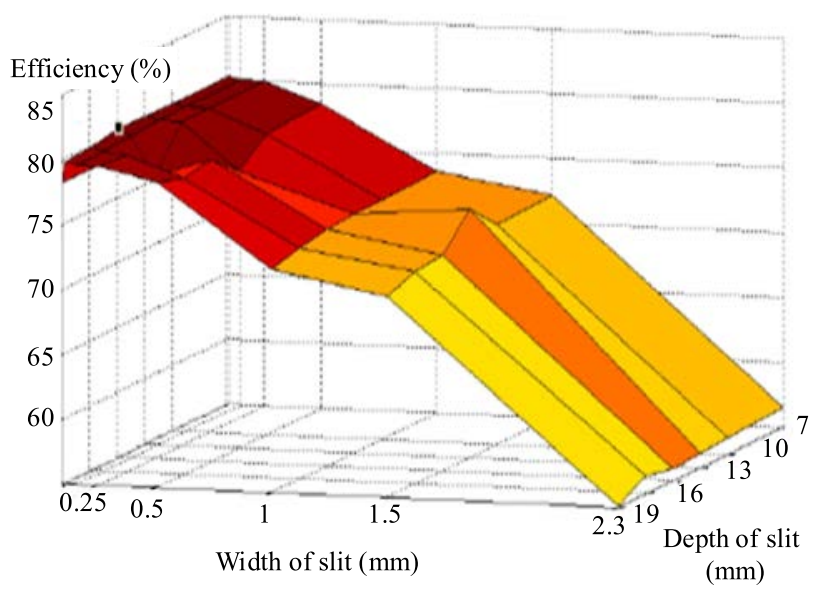

Fig. 4. The efficiency charts for the motor models in different slit depth and width

When the stator and rotor channel height values were considered, it was determined that the suitable slit value for both stator and rotor should be nearly the same height value as channel height value. It was observed that flux lines caused zigzag flux and completed their circuits around the slits in the models in which slit depth was smaller the channel height values. However, in the models in which the slit depth is higher, since the slits entered into the stator and rotor yokes, they caused saturation in these parts [12].

The efficiency findings about the 48 different motor models produced for the slit optimisation in the proposed slitted motor were presented in Tab. 4 and Figure 6 . These findings easily showed the best value of the parameter researched.

The efficiency charts obtained from slitted structure motor models were presented in Figure 6 according to their slit depth and width [13].

When the three dimensional charts obtained from 48 different models were examined, it was seen that the motor model that had $15 \mathrm{~mm}$ slit depth and $0.1 \mathrm{~mm}$ slit width had the best efficiency and as the slit depth and width increased the efficiency value decreased. 


\section{CONCLUSION}

The motor models reformed with the proposed shape were analyzed with FEMM software programme that uses finite elements method and the following results were obtained. It was found at the end of the analyses that when the optimum slit width value was $0.1 \mathrm{~mm}$, motor efficiency gave better results compared with other slit width values. The increase in slit width caused saturations in motor teeth and thus caused to worsen the motor efficiency. It was decided at the end of different modelling that the depth of the slits used in the proposed slitted motor models should be almost the same height as stator and rotor height. Optimum slit value was determined as $15 \mathrm{~mm}$. It was observed that flux lines completed their circuits around the slits in the models in which slit depth was smaller the channel height values and it negatively affected the motor efficiency. However, in the models in which the slit depth is higher, since the slits entered into the stator and rotor yokes, they caused saturation in these parts.

At the end of the modelling, $1.869 \%$ improvement was obtained in the motor models that had $15 \mathrm{~mm}$ slit depth and $0.1 \mathrm{~mm}$ slit width compared with the efficiency values of reference model at nominal operation point.

\section{Acknowledgement}

This work was supported from Sakarya University Scientific Research Project.

\section{REFERENCES}

[1] FALKNER, H.: : Promoting High Efficiency Motors in Europe, The Role of the Copper Industry, ETSU, European Copper Institute (2000), 13-26.

[2] CORino, S.-ROMERO, E.-MAntilla, L. F.: How the Efficiency of Induction Motor is Measured?, http://www.icrepq .com.

[3] AHO, T.-SIHVO, V.-NERG, J.-PYRHONEN, J.: Rotor Materials for Medium-Speed Solid-Rotor Induction Motors, Electric Machines \& Drives Conference, IEMDC '07, IEEE International (2007), 525-530.

[4] AHO, T.-NERG, J.-PYRHONEN, J.: Influence of Rotor Slit Depth on the Performence of the Solid Rotor Induction Motor, Energy Efficiency in Motor Driven Systems Conference Proceedings, 2005, pp. 81-89.

[5] ZAIM, M. E. : Application of A Nonlinear Complex Finite Element Method to the Design of Solid Rotor Reluctance Machines, IEEE Transactions on Magnetics 34 No. 5 (1998), 3592-3595.

[6] AHO, T.-NERG, J.-PYRHONEN, J.: The Effect of the Number of Rotor Slits on the Performance Characteristics of
Medium-Speed Solid Rotor Induction Motor, Power Electronics, Machines and Drives the 3rd IET International Conference (2006), 515-519.

[7] NASHIKI, M.-SATAKE, A.-KAWAI, Y.-YOKOCHI, T.OKUMA, S. : A New Flux-Barrier-Type Reluctance Motor with a Slit Rotor, IEEE Transactions on Industrial Electronics 46 No. 6 (1999), 119-1206.

[8] AKBARI, H. R.-SADEGHI, S.-ISFAHANI, A. H. : Calculation of Inductances of Induction Machines under Axial NonUniformity Conditions, Journal of Electrical Engineering 60 No. 3 (2009), 149-154.

[9] LI, L.—FOGGIA, A.—LEBOUC, A. K.-MIPO, J. C.-KOBYLANSKY, L.: Some Armature Reaction Compensation Methods Numerical Design of Experiments and Optimization for a Hybrid Excitation Machine, International Electric Machines and Drives Conference IEEE IEMDC2009, 2009, pp. 7.

10] VIOREL, I. A.-HUSAIN, I.-CHISU, I.-HEDESIU, H. C. MADESCU,-G.-SZABO, L.: Reluctance Synchronous Machine with a Particular Cageless Segmental Rotor, Proc. of ICEM 2002 (2002), 6.

[11] CHAN, S.-HAMID, M. N.: Finite-Element Study on a Two-Phase Switched Reluctance Motor with Split Rotor Poles, IEEE PEDS 2005, Power Electronics and Drives Systems PEDS 2005 International Conference, 2005, pp. 1156-1160.

[12] YETGIN, A. G.-TURAN, M.-CANAKOGLU, A. I. : A Novel Slitted Tooth Core Design to Decrease Leakage Flux in Induction Motor, Journal of The Faculty of Engineering and Architecture of Gazi University 27 No. 3 (2012), 607-614.

[13] YETGIN, A. G. : Performance Improvement of Induction Motor with Slitted Core Design, PhD Dissertation Thessis, Sakarya University, Institute of Science, Sakarya, 2010.

[14] BOLDEA, I.-NASAR, S. A.: The Induction Machine Handbook, CRC Pres LLC, Washington, DC, 2002.

Received 21 December 2012

Asim Gökhan Yetgin was born in Kütahya, Turkey, in 1979. He received the BSc and MSc degrees in 2001 and 2004 from the Department of Electrical Electronics Engineering, Selcuk University, Konya, Turkey and Dumlupinar University, Ktahya, Turkey respectively. He received $\mathrm{PhD}$ degree from Sakarya University. He is working as Assistant Professor in Department of Electrical Electronics Engineering, Dumlupinar University. His areas of research include optimization, design and modeling of electrical machines, finite element method and energy saving.

Mustafa Turan was born in Babaeski, Turkey, in 1964. He has received BS degree from Istanbul Technical University, MSc and PhD degrees from Sakarya University, Turkey in the years 1987, 1994 and 2002 respectively, in Electrical Engineering. He is a faculty member of Electrical and Electronics Engineering Department, Sakarya University, Turkey, since 2002, and currently serving as Assistant Professor. His research interests include design, performance analysis and optimization of electrical machines, power quality power system stability. 